Periodontal apsenin kombine periodontal tedavisi: Bir olgu sunumu

\section{Combined periodontal therapy of periodontal abscess: A case report}

\author{
Dr. Hafize Öztürk Özener \\ Marmara Üniversitesi Diş Hekimliği Fakültesi Periodontoloji \\ Anabilim Dalı, İstanbul
}

\section{Yrd. Doç. Dr. H. Selin Yıldırım}

Marmara Üniversitesi Diş Hekimliği Fakültesi Periodontoloji Anabilim Dalı, İtanbul

\section{Prof. Dr. Leyla Kuru}

Marmara Üniversitesi Diş Hekimliği Fakültesi Periodontoloji Anabilim Dalı, İtanbul

Geliş Tarihi : 8 Aralık 2015

Kabul Tarihi : 22 Ocak 2016

\section{Yazışma adresi:}

Yrd. Doç. Dr. H. Selin Yıldırım

Marmara Üniversitesi Diş Hekimliği Fakültesi Periodontoloji

Anabilim Dalı

Başıüyyük/Maltepe, ISTANBUL

E-mail: yildirimselin@hotmail.com

\section{ÖZET}

Periodontal apse, periodontal dokuların hızlı yıkımılla karakterize akut iltihabi bir lezyondur. Bu vaka raporunda alt molar dişte gelişen akut periodontal apsenin kombine periodontal tedavisinin sunulması amaçlanmıı̧ıı. Kliniğimize alt sağ bölgesinde ağrı ve şişlik şikayetiyle başvuran 24 yaşındaki sistemik olarak sağlıkı kadın hastanın klinik muayenesinde 46 nolu dişin vestibülünde ödemli, kırmızı, düz ve parlak yüzeyli alveol mukozası görüldü. Periodontal sondayla muayenede vestibülde $12 \mathrm{~mm}$ sondalama derinliği (SD) tespit edilirken radyolojik olarak periodontal dokuların normal olduğu saptandı. Lezyonaakutperiodontal apse teşhisi kondu. IIlk olarak apse drenajı ve başlangıç periodontal tedavi (BPT) ile birlikte analjezik ve kombine antimikrobiyal tedaviye (amoksisilin + klavulanik asit 1000 mg 2、1, Metronidazol 500 mg 2、1, 1 hafta) başlandı. BPT sonrası keratinize yapışık dişeti elde etmek amacıyla serbest dişeti grefti uygulandı ve 6 hafta sonra 44, 45 ve 46 nolu dişlerin vestibül yüzeylerindeki dişeti çekilmelerinin tedavisi için mine matriks türevleri (EMDOGAiN ${ }^{\circledR}$ ) ile birlikte kuronale kaydırılan flep operasyonu yapıldı. 44, 45 ve 46 nolu dişlerin midbukkalinde sırasıyla SD başlangıçta $2 \mathrm{~mm}$, $3 \mathrm{~mm}, 12 \mathrm{~mm}$ ve operasyondan 6 ay sonra $1.5 \mathrm{~mm}, 1 \mathrm{~mm}$, $1.5 \mathrm{~mm}$, dişeti çekilmesi dikey boyutu başlangıçta $2 \mathrm{~mm}, 3.5$ $\mathrm{mm}, 3.5 \mathrm{~mm}$ iken operasyon sonrası $1 \mathrm{~mm}, 1 \mathrm{~mm}, 0.5 \mathrm{~mm}$ olarak ölçüldü. Periodontal apselerin kombine periodontal tedavisiyle estetik ve fonksiyonel olarak başariı sonuçlar elde edilebilmektedir.

Anahtar Kelimeler: Dişeti çekilmesi, mine matriks türevleri, periodontal apse

\section{SUMMARY}

Periodontal abscess is an acute inflammatory lesion characterized by rapid destruction of periodontal tissues. This case report is aimed to present the combined periodontal therapy of a periodontal abscess in mandibular molar. Twenty four year-old systemically healthy female patient was attended to our clinic with complaints of pain and swelling at right mandibular region. Edematous, red, smooth and shiny alveolar mucosa was observed. A probing depth (PD) of $12 \mathrm{~mm}$ was measured on the vestibule of tooth \#46 with normal radiographical findings; acute periodontal abscess was diagnosed. Firstly abscess drainage and initial periodontal treatment (IPT) were applied with adjunctive antimicrobial therapy. After IPT, in order to obtain keratinized attached gingiva, free gingival graft procedure was performed. Six weeks after the surgery enamel matrix derivatives (EMDOGAIN ${ }^{\circledR}$ ) with coronally advanced flap was applied for the treatment of gingival recession on the vestibular surface of the teeth \#44, \#45 and \#46. PD of the teeth \#44, \#45 and \#46 were $2 \mathrm{~mm}, 3$ 
mm, $12 \mathrm{~mm}$ at baseline, respectively, and $1.5 \mathrm{~mm}, 1 \mathrm{~mm}$ $1.5 \mathrm{~mm}$ at 6 months; recession depth of the teeth \#44, \#45 and \#46 were $2 \mathrm{~mm}, 3.5 \mathrm{~mm}, 3.5 \mathrm{~mm}$ at baseline, and 1 mm, $1 \mathrm{~mm}, 0.5 \mathrm{~mm}$ at 6 months, respectively. Aesthetically and functionally successful results can be obtained with combined approach in the treatment of periodontal abscess.

Keywords: Enamel matrix derivatives, gingival recessions, periodontal abscess

\section{GiRiş}

Periodontal cebe komşu dokularda oluşan lokalize pürülan bir enfeksiyon olan periodontal apse, periodontal ligament ve alveol kemiğinde yıkıma yol açabilmektedir. ${ }^{1}$

Periodontal apselerin siniflandırımasında lezyonun lokalizasyonu² ve seyri göz önünde bulundurulur.

Periodontal apseler lokalizasyonuna göre dişeti apsesi ve periodontal apse olmak üzere ikiye ayrımaktadır. Sadece marjinal ve interdental dişetinin etkilendiği ve subgingival alandaki yabancı cisimle ilişkili olabilen dişeti apseleri lokalize ve ağrııdır. Bu durum sağlıklı dişetinde de meydana gelebilir. ${ }^{3}$ Periodontal apseler derin periodontal dokuları etkileyen, derin ceplerin, furkasyon ve kemik defektlerinin olduğu ve genellikle mukogingival sınırın ötesinde yer alan ağrılı lezyonlardır. ${ }^{4}$ Periodontal apseler akut veya kronik olabilir. Akut periodontal apseler genellikle ağrı, palpasyona karşı duyarlıık ve hafif basınç varlığında süpürasyon gibi belirtiler gösterir. Kronik periodontal apse fistül yoluyla ilişkilidir ve hastaların hafff şikayetlerine rağmen genellikle asemptomatiktir. $^{5}$ Periodontal apseler lokalize veya generalize olarak görülebilir. ${ }^{6}$ Lokalize periodontal apse genellikle periodontal cebin drenajını engelleyen lokal faktör varlığı ile ilişkilidir. Generalize periodontal apselerin ise kontrol altında olmayan diabetes mellitus gibi sistemik problemleri olan hastalarda görülebildiği bildirilmiştir. ${ }^{6-8}$ Ayırıcı tanıda dişin vitalite testi önemli bir yer tutar; periodontal apsede diş vitaldir.

Periodontal apseler periodontal hastalık görülen veya periodontal olarak sağlıklı bölgelerde meydana gelebilir. Periodontal hastalıkla birlikte görülen periodontal apseler, kompleks ceplerin, furkasyon ve vertikal defektlerin varlığında periodontal hastalığın akut olduğu dönemlerde görülebilmektedir.9-11 Ayrıca subgingival bölgedeki mikrobiyal floranın değiş̧imi, artan bakteri virulansı veya azalan konak yanıtı ile birlikte görülen süpürasyonun drene olamaması sonucu kaynak yazımı oluşabilmektedir. ${ }^{4}$ Periodontitis hastalarında periodontal apseler farklı yollarla meydana gelebilir: (1) Başlangıç periodontal tedavi (BPT) sonrası, diştaşı doku içerisine itilebilir ${ }^{12}$ veya derin ceplerden diştaşının tam olarak uzaklaştırılamaması nedeniyle cebin kuronal kısmında drenaj gerçekleşemediği için oluşabilir³. (2) cerrahi periodontal tedavi sonrası, rejenerasyon amaçlı kullanılan membran ya da sütur gibi yabancı cisimlerin varlığı ile ilişkili olabilir ${ }^{14}$; (3) tedavi edilmeyen ${ }^{12}$, inatçı ${ }^{15}$ periodontitis vakalarında ve destekleyici periodontal tedavide akut alevlenme dönemlerinde ${ }^{16-18}$ meydana gelebilir. (4) Subgingival temizlik yapılmadan sistemik antibiyotik verilen şiddetli periodontitis vakalarında ${ }^{6-8}$ fırsatçı bakterilerin $\operatorname{artması}^{8}$ sebebiyle periodontal apse oluşabilir.

Sağlıklı bölgelerde periodontal apse ortodontik lastik, diş ipi parçası, kürdan parçası gibi yabancı cisim varlığında ya da endodontik olarak perforasyon, eksternal kök rezorpsiyonu veya kırık diş gibi kök yüzey değişikliklerine bağlı olarak da meydana gelebilmektedir. ${ }^{4}$

Periodontal apselerin mikrobiyolojisi değerlendirildiğinde, gram-negatif bakterilerin gram-pozitif bakteriler üzerinde ve çubukların koklar üzerinde baskın olduğu saptanmıştır. ${ }^{11}$ Periodontal apselerde en yaygın bakteri türü Porphyromonas ginigivalis'tir., 11,19-23 Prevotella intermedia, Prevotella melaninogenica, Fusobacterium nucleatum, Tannerella forsythia, Treponema spp. Parvimonas micra, Actinomyces spp. ve Bifidobacterium spp. türleri de sıklıkla tespit edilmektedir. ${ }^{4}$

Periodontal apselerin belirtileri; hafif rahatsızlıktan şiddetliye kadar değişebilen ağrı, hassas dişeti, şişlik, mobilite, dişte yükselme ve palpasyona duyarııık, süpürasyon ve dişetinde kanamadır. Radyografik incelemede normal görünüm ya da bir miktar kemik kaybı (eğer apse önceden var olan periodontal cepte oluşursa) ortaya çıkarabilir

Periodontal apse tanısı muayene sırasındaki klinik ve radyolojik bulgular ile birlikte hastanın şikayeti ve hastalığın belirtilerinin değerlendirilmesine dayanmaktadır. ${ }^{24}$

Periodontal apse tedavisi, akut durumun kontrolü, doku yıkımının durdurulması ve semptomların kontrol altına alınmasl; ve özellikle periodontitisli hastalarda önceden var olan ve/veya rezidüel lezyonun tedavisi olmak üzere iki ayrı tedavi fazı içermelidir. Akut durumun kontrolü için dört terapötik alternatif önerilmiştir: diş çekimi, drenaj ve debridman, sistemik veya lokal antimikrobiyal tedavi ve cerrahi tedavi. Çok sayıda tedavi protokolleri önerilmiştir, ancak kesin bir yaklaşım için yeterli bilimsel kanıt yoktur Sistemik durum ve apsenin erişilebilirliği uygunsa öncelikle drenaj yapılması gerektiği nettir. Drenajın ya da sistemik durumun uygun olmadığı durumlarda, sistemik antimikrobiyaller ile tedavi düşünülmelidir. ${ }^{4}$ 
Bu vaka raporunda; periodontal cerrahi tedavi sonucu oluştuğu düşünülen akut periodontal apsenin cerrahi olmayan ve olan periodontal tedavisinin sunulması amaçlanmıştır.

\section{OLGU SUNUMU}

Marmara Üniversitesi Diş Hekimliği Fakültesi Periodontoloji Anabilim Dalı́na alt sağ bölgede ağı ve şişlik şikayetiyle başvuran 24 yaşındaki sistemik olarak sağlıklı kadın hastanın alınan anamnezinde ilgili bölgeden 2.5 yıl önce cerrahi periodontal tedavi gördüğü öğrenildi. Klinik muayenede bölgedeki 46 nolu dişin alveol mukozasının ödemli, kırmızı, düz ve parlak yüzeyli olduğu ve dişin vestibül yüzeyinde keratinize yapışık dişetinin bulunmadığı tespit edildi. Hasta, 46 nolu dişte yatay perküsyonda hafff rahatsızlık hissetti ve diş termal teste normal cevap verdi. 46 nolu dişin mezial kökünün vestibülünde 12 mm sondalama derinliği (SD) tespit edilirken apsenin sondalama esnasında drene olduğu gözlendi (Resim 1 a, b, c). Radyolojik olarak herhangi bir patoloji saptanmayan (Resim 1d) lezyona akut periodontal apse teşhisi konuldu.
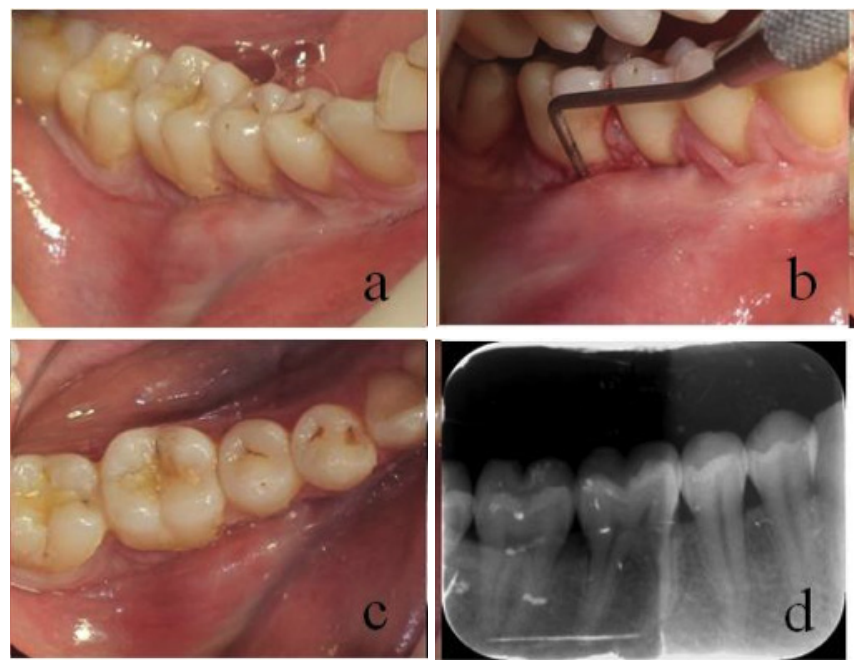

Resim 1. (a) Periodontal apsenin vestibülden görüntüsü, (b) Periodontal apsenin periodontal sonda ile muayenesi, (c) Periodontal apsenin okluzalden görüntüsü, (d) Bölgenin radyografik görüntüsü.

Hastanın tedavisinde iltihabın ortadan kaldırıması, periodonsiyumda oluşan yıkımın yeniden yapılandırıması ve hastalığın tekrarının önlenmesi amaçlandı. Bu amaç doğrultusunda ilk seans lokal anestezi altında apse drenajı ile birlikte diş ve kök yüzeyi düzleştirmesini içeren BPT yapilarak analjezik (naproksen sodyum 275 mg 2X1, 1 hafta) ve kombine antimikrobiyal tedaviye (amoksisilin + klavulanik asit 1000 mg 2X1, metronidazol 500 mg 2X1, 1 hafta) başlandı. BPT haftada bir seans olmak üzere toplam
3 hafta uygulandı (Resim 2). Illgili bölgede keratinize yapışık dişeti yetersizliği nedeniyle BPT sonrası 45 ve 46 nolu dişlerin

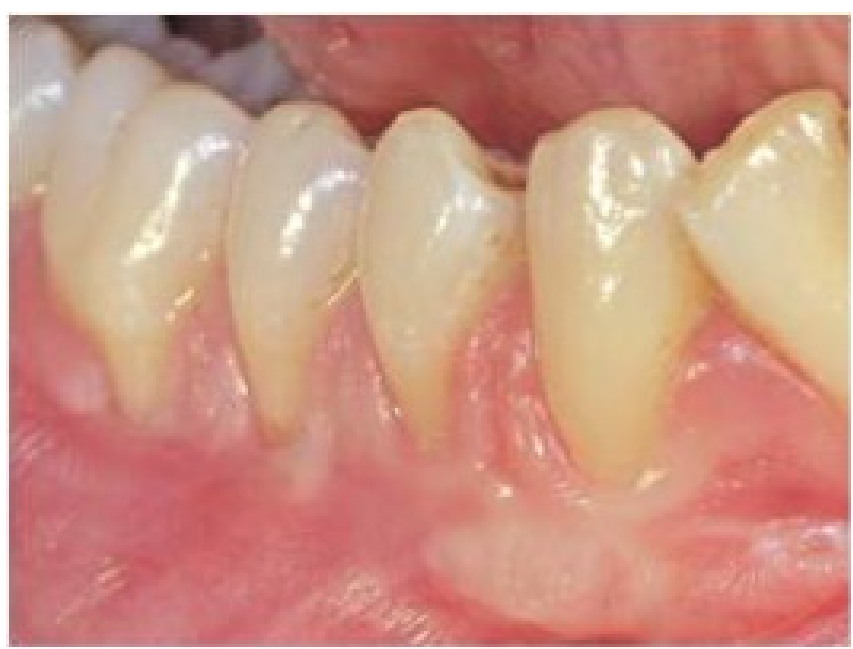

Resim 2. Başlangıç periodontal tedavi sonrası bölgenin ağız içi görüntüsü.

vestibül yüzeylerine serbest dişeti grefti ameliyatı yapıldı (Resim 3 a, b, c, d, e), ve 1 hafta sonra dikişler alındı (Resim $3 \mathrm{f}, \mathrm{g}$ ). Bu operasyon sonucu 45 nolu dişin midbukkalinde $6 \mathrm{~mm}, 46$ nolu dişin midbukkalinde ise $5 \mathrm{~mm}$ keratinize yapışık dişeti elde edildi. Operasyondan 6 hafta sonra 44,

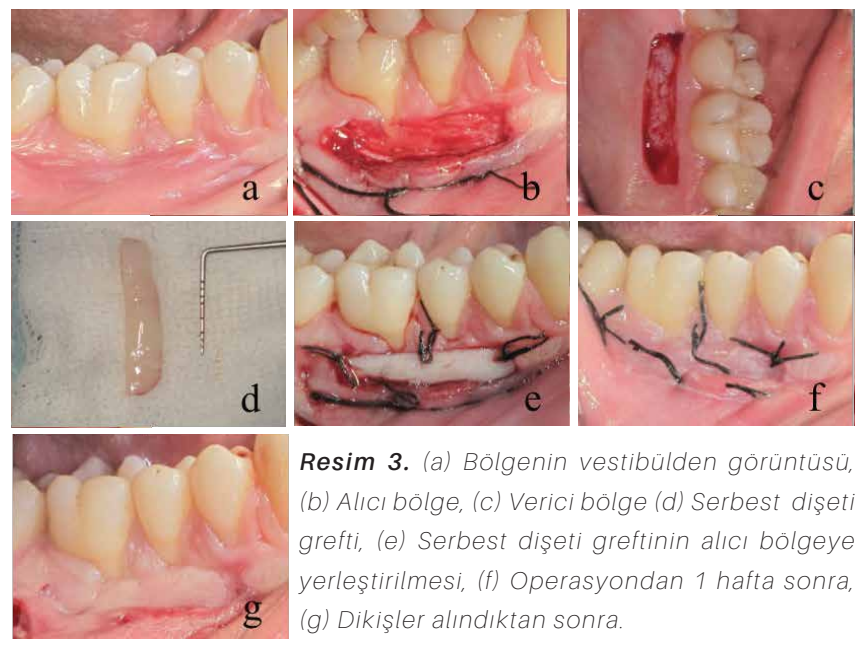

45 ve 46 no'lu dişlerin vestibül yüzeylerindeki Miller sınıf ॥ generalize diş eti çekilmelerinin tedavisi için flep kaldırıldıktan sonra dehisens varlığı sebebiyle mine matriks türevleri (EMDOGAIN ${ }^{\circledR}$ ) ile birlikte Zucchelli ve ark.'nın ${ }^{25}$ modifiye ettiği kuronale kaydırılan flap operasyonu yapıldı (Resim 4a, b, c, d, e, f). Operasyon sonrası hastaya sistemik antibiyotik (amoksisilin + klavulanik asit 1000 mg 2X1, 1 hafta) ve \%0.2'lik klorheksidin diglukonat içeren ağız gargarası (2X1, 2 hafta) verildi. Operasyondan 2 hafta sonra dikişler alındı. Hastanın 6 aylık takibinde sorunsuz klinik iyileşmeye (Resim 5) klinik parametrelerdeki olumlu gelişmeler eşlik etti (Tablo 1). 


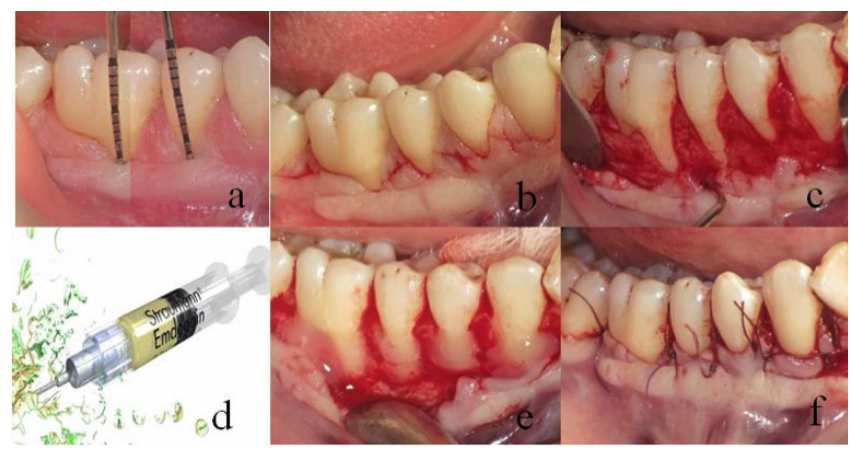

Resim 4. (a) 45 ve 46 nolu dişlerin dişeti çekilmesi dikey boyutu başlangıç ölçümü (b) Ensizyon, (d) Flep kaldırılması ve kök yüzeylerindeki dehiscence, (e) Emdogain ve (f) Uygulanması, (g) Flebin kuronale kaydırılarak 4.0 dikişlerle sabitlenmesi.

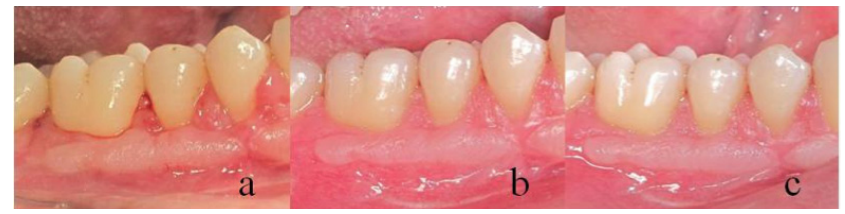

Resim 5. Operasyondan (a) 2 hafta, (b) 6 hafta, (c) 6 ay sonra.

\begin{tabular}{|c|c|c|c|c|}
\hline Parametre & Zaman & \#44 & \#45 & \#46 \\
\hline \multirow{2}{*}{$\begin{array}{c}\text { Sondalama } \\
\text { derinliği (mm) }\end{array}$} & Başlangıç & 2 & 3 & 12 \\
\cline { 2 - 5 } & $\mathbf{6 . ~ a y ~}$ & 1.5 & 1 & 1.5 \\
\cline { 2 - 5 } & Fark & 0.5 & 2 & 10.5 \\
\hline $\begin{array}{c}\text { Dişeti çekilmesi } \\
\text { dikey boyutu } \\
\text { (mm) }\end{array}$ & Başlangıç & 2 & 3.5 & 3.5 \\
\cline { 2 - 5 } & $\mathbf{6 . ~ a y ~}$ & 1 & 1 & 0.5 \\
\cline { 2 - 5 } & Fark & 1 & 2.5 & 3 \\
\hline \multirow{2}{*}{$\begin{array}{c}\text { Keratinize dişeti } \\
\text { dikey boyutu } \\
\text { (mm) }\end{array}$} & Başlangıç & 3 & 0 & 0 \\
\cline { 2 - 5 } & $\mathbf{6 . ~ a y ~}$ & 3 & 6 & 5 \\
\cline { 2 - 5 } & Fark & 0 & 6 & 5 \\
\hline
\end{tabular}

\section{TARTIŞMA}

Periodontal apseler genellikle ağrı ve şişlik sebebiyle hastaları diş kliniğine getiren acil durumlardan biri olup periodontal dokularda lokalize pürülan enflamasyon varlığı ile karakterizedir. ${ }^{26}$ Periodontal apseyi apikal apseden ayırmada klinik muayene, vitalite testi, radyografik bulgular ve lezyonun lokalizasyonu dikkate alınır. Lezyonun dişeti kenarı ile ilişkili olması periodontal apsenin en önemli klinik belirtisidir. ${ }^{26}$ Bu vaka raporunda, kliniğimize ağrı ve şişlik şikayetiyle başvuran hastanın klinik, vitalometrik ve radyografik muayenesinde 46 numaralı dişin vestibülünde akut lokalize periodontal apse teşhis edilmiştir.

Periodontal apse oluşumunun farklı mekanizmaları vardır. Cerrahi sırasında bölgeden diştaşının yetersiz uzaklaştırılması, bölgede sütur, rejeneratif materyaller veya periodontal pat varlığının yabancı cisim reaksiyonu göstermesi gibi nedenlerle periodontal cerrahi sonrası periodontal apselerin gelişebileceği literatürde yer bulmuştur. ${ }^{26}$ Ayrıca keratinize yapışık dokunun az ve vestibül derinliğin sığ olması çiğneme sırasında gıdaların birikmesine ve ağız bakımı sırasında zorluklara neden olur. ${ }^{27}$ Vakamızın anamnezinden yola çıkarak önceden yapilan periodontal cerrahi tedavi sonrası yapışık keratinize doku yetersizliliğine bağlı olarak ilgili bölgede periodontal apse geliştiği düşünülmektedir.

Akut periodontal apse tedavisi drenaj ve antibiyotik tedavisini içeren akut durumun tedavisiyle ${ }^{26}$ birlikte mikrobiyal dental plak kontrolü, diş ve kök yüzeyi temizliği ve kök yüzeyi düzleştirmesi, oklüzal uyumlamayı içeren BPT ve takiben gerekliyse periodontal cerrahi ile sağıklı bir ağız ortamının sağlanması ve bu ortamın korunması için belli aralıklarla kontrolünün yapıımasını içerir. ${ }^{28}$ Bu vakada da öncelikle akut durum periodontal cepten direnaj sağlanarak ve sistemik antibiyotik tedavisi ile kontrol altına alındı. BPT sonrası apse oluşumuna ortam hazılladığı düşünülen keratinize yapışık doku yetersizliğinin ve bölgedeki çoklu dişeti çekilmesinin periodontal cerrahi tedavisi yapıldı.

Keratinize doku günümüz bilgileri dahilinde, mekanik, bakteriyel ve cerrahi travmaya karşı dayanıklılık sağlar, estetik manipülasyona imkan tanır, dişeti çekilmesini önler, papillaları korur, ağız bakımı işlemlerini kolaylaştııı, kas ve frenum çekmelerini engeller. ${ }^{29-31}$ Bu vakada keratinize yapışık dişeti miktarını artırımak için serbest dişeti grefti operasyonu yapildı.

\section{SONUÇ}

Periodontal apselerin kombine periodontal tedavisiyle estetik ve fonksiyonel olarak başarılı sonuçlar elde edilebilmektedir. 


\section{KAYNAKLAR}

1. Consensus Report. Abscesses of the periodontium, Ann Periodontol. 1999; 4: 83

2. Gillette $W B$, van House R L. Ill effects of improper oral hygeine procedure, J Am Dent Assoc. 1980; 101: 476-480

3. AhIDR, Hilgeman J L, Snyder J D. Periodontal emergencies, Dent Clin North Am. 1986; 30: 459-472

4. Herrera D, Alonso B, de Arriba L, Santa Cruz I, Serrano C, Sanz M. Acute periodontal lesions, Periodontol 2000. 2014, 65: $149-177$

5. Pini Prato G P, Cortellini P, Clauser C. Fibrin and fibronectin sealing system in a guided tissue regeneration procedure. A case report, J Periodontol. 1988; 59: 679-683

6. Topoll H H, Lange D E, Muller R F. Multiple periodontal abscesses after systemic antibiotic therapy, J Clin Periodontol. 1990; 17: 268-272

7. Helovuo H, Paunio K. Effects of penicillin and erythromycin on the clinical parameters of the periodontium, $J$ Periodontol. 1989; 60: 467-472

8. Helovuo $H$, Hakkarainen $K$, Paunio $K$. Changes in the prevalence of subgingival enteric rods, staphylococci and yeasts after treatment with penicillin and erythromycin, Oral Microbiol Immunol. 1993; 8: 75-79

9. DeWitt $G$ V, Cobb C M, Killoy W J. The acute periodontal abscess: microbial penetration of the soft tissue wall, Int $J$ Periodontics Restorative Dent. 1985; 5: 38-51

10. Kareha M J, Rosenberg E S, DeHaven H. Therapeutic considerations in the management of a periodontal abscess with an intrabony defect, J Clin Periodontol. 1981; 8. $375-386$

11. Newman $M G$, Sims $T N$. The predominant cultivable microbiota of the periodontal abscess, J Periodontol. 1979, 50: $350-354$

12. Dello Russo NM. The post-prophylaxis periodontal abscess. etiology and treatment, Int J Periodontics Restorative Dent. 1985; 5: 28-37

13. Kaldahl W B, Kalkwarf K L, Patil K D, Molvar M P, Dyer J K. Long-term evaluation of periodontal therapy: I. Response to 4 therapeutic modalities, J Periodontol. 1996; 67: 93-102

14. Garrett S, Polson A M, Stoller N H, Drisko C L, Caton J G, Harrold C Q, Bogle G, Greenwell H, Lowenguth R A, Duke $S$ P, DeRouen T A. Comparison of a bioabsorbable GTR barrier to a non-absorbable barrier in treating human class II furcation defects. A multi-center parallel design randomized single-blind trial, J Periodontol. 1997; 68: 667-675

15. Fine D H. Microbial identification and antibiotic sensitivity testing, an aid for patients refractory to periodontal therapy. A report of 3 cases, J Clin Periodontol. 1994; 21: 98-106

16. Chace R, Sr., Low S B. Survival characteristics of periodontally-involved teeth: a 40-year study, J Periodontol. 1993: 64: 701-705
17. Mcleod D E, Lainson P A, Spivey J D. Tooth loss due to periodontal abscess: a retrospective study, J Periodontol. 1997; 68: 963-966

18. Silva GL, Soares R V, Zenobio E G. Periodontal abscess during supportive periodontal therapy: a review of the literature, J Contemp Dent Pract. 2008; 9: 82-91

19. Eguchi T, Koshy G, Umeda M, Iwanami T, Suga J, Nomura Y, Kawanami M, Ishikawa I. Microbial changes in patients with acute periodontal abscess after treatment detected by PadoTest, Oral Dis. 2008; 14: 180-184

20. Hafstrom C A, Wikstrom MB, Renvert SN, Dahlen G G. Effect of treatment on some periodontopathogens and their antibody levels in periodontal abscesses, J Periodontol. 1994; 65: 1022-1028

21. Herrera D, Roldan S, Gonzalez I, Sanz M. The periodontal abscess (I). Clinical and microbiological findings, J Clin Periodontol. 2000; 27: 387-394

22. Jaramillo A, Arce R M, Herrera D, Betancourth M, Botero J E, Contreras A. Clinical and microbiological characterization of periodontal abscesses, J Clin Periodontol. 2005; 32. 1213-1218

23. van Winkelhoff A J, Carlee A W, de Graaff J. Bacteroides endodontalis and other black-pigmented Bacteroides species in odontogenic abscesses, Infect Immun. 1985; 49. 494-497

24. Corbet E F. Diagnosis of acute periodontal lesions, Periodontol 2000. 2004; 34: 204-216

25. Zucchelli G, De Sanctis M. Treatment of multiple recessiontype defects in patients with esthetic demands, J Periodontol. 2000; 71: 1506-1514

26. Herrera D, van Winkelhoff, J., Sanz M., Abscesses in periodontium, in: J L Niklaus P. Lang (Ed.) Clinical periodontology and implant dentistry, 2015, pp. 463

27. Miller $P D, J$ r. Regenerative and reconstructive periodontal plastic surgery. Mucogingival surgery, Dent Clin North Am. 1988; 32: 287-306

28. Caffesse $R G$, Mota L F, Morrison E C. The rationale for periodontal therapy, Periodontol 2000. 1995; 9: 7-13

29. Wennstrom J, Lindhe J. Role of attached gingiva for maintenance of periodontal health. Healing following excisional and grafting procedures in dogs, J Clin Periodontol. 1983; 10: 206-221

30. Wennstrom J, Lindhe J, Nyman S. The role of keratinized gingiva in plaque-associated gingivitis in dogs, J Clin Periodontol. 1982; 9: 75-85

31. Wennstrom J, Lindhe J, Nyman S. Role of keratinized gingiva for gingival health. Clinical and histologic study of normal and regenerated gingival tissue in dogs, J Clin Periodontol. 1981; 8: 311-328 